\title{
Endovascular Treatment of 300 Consecutive Middle Cerebral Artery Aneurysms: Clinical and Radiologic Outcomes
}

A.M. Mortimer, M.D. Bradley, P. Mews, A.J. Molyneux, and S.A. Renowden

\begin{abstract}
BACKGROUND AND PURPOSE: There is controversy as to the best mode of treating MCA aneurysms. We report the results of a large endovascular series of patients treated at our center.
\end{abstract}

MATERIALS AND METHODS: This study was a retrospective analysis of a prospectively acquired data base. All patients with saccular MCA aneurysms treated between November 1996 and June 2012 were included. World Federation of Neurosurgical Societies grade, aneurysm site, size, and aneurysm neck size were recorded, along with clinical outcome assessed with the Glasgow Outcome Scale and radiographic occlusion assessed with the Raymond classification at 6 months and 2.5 years.

RESULTS: A total of 295 patients with 300 MCA aneurysms were treated including 244 ruptured aneurysms (80.7\%). The technical failure rate was $4.3 \%$ (13 patients). Complete occlusion or neck remnant was achieved in 264 (91.4\%). Complications included rupture in 15 patients (5\%), thromboembolism in 17 patients (5.7\%), and early rebleeding in 3 patients (1\%). Overall permanent procedural-related morbidity and mortality were seen in 12 patients $(7.8 \%)$. Of the ruptured aneurysms, $189(79.4 \%)$ had a favorable clinical outcome (Glasgow Outcome Scale score, $4-5$ ). A total of 33 patients (13.6\%) died. On initial angiographic follow-up, aneurysm remnant was seen in 18 aneurysms ( $8.1 \%)$. A total of 13 patients $(4.3 \%)$ were re-treated.

CONCLUSIONS: Our experience demonstrates that endovascular treatment of MCA aneurysms has an acceptable safety profile with low rates of technical failure and re-treatment. Therefore, coiling is acceptable as the primary treatment of MCA aneurysms.

ABBREVIATIONS: EVC = endovascular coiling; GOS = Glasgow Outcome Scale; ISAT = International Subarachnoid Aneurysm Trial; WFNS = World Federation of Neurosurgical Societies

$\mathrm{T}$ he International Subarachnoid Aneurysm Trial (ISAT) demonstrated an absolute $6.9 \%$ reduction in the rate of death or dependency at 1 year for patients treated with endovascular coiling (EVC). ${ }^{1}$ ISAT did not, however, address the specific issue of patients with MCA aneurysms, who represented only 303 (14.1\%) of the 2143 enrolled patients. This has resulted in controversy as to the best mode of treatment of aneurysms at this location. Surgical clipping remains the standard treatment in many institutions. The anatomic location aids surgical access, and in some cases, surgery facilitates hematoma evacuation. There is also a perceived increased risk for EVC at this site because these aneurysms are often wide-neck and have branches arising from the neck. ${ }^{2,3}$ Recently, several surgical series have been published that

Received March 14, 2013; accepted after revision August 16.

From the Department of Neuroradiology, Frenchay Hospital, Bristol, United Kingdom.

Please send correspondence to Alex Mortimer, Department of Neuroradiology, Frenchay Hospital, Frenchay Park Rd, Bristol, UK, BS161LE; e-mail:

alex_mortimer@hotmail.com

http://dx.doi.org/10.3174/ajnr.A3776 demonstrate excellent clinical results with low rates of morbidity and mortality. ${ }^{4-7}$ Therefore, we analyzed the strategy at our institution where EVC is the first-line therapy for aneurysm treatment at any location and focused on the more controversial MCA aneurysms.

\section{MATERIALS AND METHODS Patient Population}

This was an observational, prospectively collated study of 295 consecutive patients referred to our institution for endovascular treatment of ruptured and unruptured MCA aneurysms. All patients underwent primary EVC during a 15.5-year period (between November 1996 and June 2012). All patients with $\mathrm{SAH}$ were considered for EVC as the primary treatment technique when a consultant interventional neuroradiologist was available. Elective cases were discussed at our institutional neurovascular multidisciplinary meeting. Patients with fusiform or dissecting aneurysms and those treated with primary parent vessel occlusion were excluded from this study. Patient information, aneurysm characteristics, details of treatment, 
and clinical course were entered prospectively into a data base and subsequently analyzed.

SAH was confirmed by cranial CT or lumbar puncture and CSF analysis. Of those with unruptured aneurysms, 21 patients with 23 aneurysms had previous SAH and delayed treatment of additional MCA aneurysms or SAH that was clearly the result of another aneurysm, with the additional MCA aneurysm treated in the same procedure. Thirty-two patients with $33 \mathrm{MCA}$ aneurysms diagnosed incidentally were also treated.

\section{Endovascular Procedure}

All procedures were performed by consultant interventional neuroradiologists (S.A.R., M.D.B., and A.J.M. with 5, 3, and 20 years of endovascular experience when they started coiling patients within the study period, respectively). EVC was performed by use of conventional techniques with the patients under general anesthesia and systemic heparinization. A bolus of 3000-5000 IU of heparin was followed by continuous infusion via the catheterflushing system at a concentration of $5 \mathrm{IU} / \mathrm{mL}$. The aim was to place coils sequentially into the aneurysmal sac to the point of angiographic occlusion. Most coils deployed were bare platinum (Boston Scientific, now Stryker, Kalamazoo, Michigan; Micrus, now Codman Neurovascular, Raynham, Massachusetts; ev3, now Covidien, Dublin, Ireland). After diagnostic angiography, the aneurysm was selectively catheterized with a microcatheter by use of standard techniques, through a guide catheter positioned in the internal carotid artery.

Where necessary, balloon remodeling ( 12 cases primary treatment, 4 cases re-treatment) and stent-assisted coil embolization ( 1 case primary treatment, 1 case re-treatment) were used for the treatment of wide-neck aneurysms. Intravenous aspirin (500 mg) was used as a prophylaxis to prevent thromboembolic complications in both ruptured and unruptured aneurysms, administered after initial coil deployment when a degree of protection had been attained. Intravenous aspirin was also administered if a stent was deployed. Technical failure was defined as an attempted embolization procedure during which coils could not be deployed safely. Any procedural or other subsequent complication was recorded in addition to any deterioration in the patient's neurologic status after the procedure. Craniotomy and hematoma evacuation or decompressive hemicraniectomy were performed to manage hematoma/herniation, after coil embolization.

\section{Aneurysms Treated}

The aneurysm responsible for hemorrhage was identified by blood distribution on CT, aneurysm appearance, and vasospasm distribution. This aneurysm was treated first. Additional aneurysms were treated during the same procedure or after recovery from hemorrhage. If it was not possible to clearly identify the ruptured aneurysm, all possible candidates were treated initially, and aneurysms were classified as ruptured. If contralateral aneurysms were treated at a later date, these were classified as unruptured.

\section{Clinical and Radiologic Follow-Up}

Clinical outcome was independently obtained for all at a 3- to 6-month clinic visit with a specialist neurovascular nurse practi-
Table 1: Descriptive data for the study population

\begin{tabular}{lcc} 
& \multicolumn{2}{c}{ Type of Aneurysm } \\
\cline { 2 - 3 } \multicolumn{1}{c}{ Patient Characteristics } & Unruptured & Ruptured \\
\hline Number of patients $(n=295)$ & 53 & 242 \\
Number of aneurysms $(n=300)$ & 56 & 244 \\
Mean (SD) age $(y)$ & $52.7(9.6)$ & $53.9(12.4)$ \\
Median (IQR) age $(y)$ & $55.0(13.5)$ & $53.0(17)$ \\
Age range $(y)$ & $29-72$ & $21-84$ \\
No. of women (\%) & $38(73.1)$ & $158(65.3)$ \\
WFNS scale, $n(\%)$ & & \\
1 & - & $136(56.2)$ \\
2 & - & $38(15.6)$ \\
3 & - & $25(10)$ \\
4 & - & $21(8.6)$ \\
5 & - & $22(9.1)$ \\
Fisher grade, $n(\%)$ & & \\
I & - & $11(4.5)$ \\
II & - & $20(8.3)$ \\
III & - & $103(42.6)$ \\
IV & - & $108(44.6)$ \\
\hline
\end{tabular}

tioner and was assessed by use of the Glasgow Outcome Scale (GOS). Each patient was scheduled to undergo either cerebral angiography (before 2004: 48 patients) or MRA (since 2004: 174 patients) at 6 months after treatment and then at approximately 30 months after initial treatment. If early recurrence was anticipated, initial follow-up was obtained earlier. If recurrence was demonstrated on MRA, formal conventional angiography was performed.

The degree of aneurysm occlusion was assessed on immediate postembolization angiography and on follow-up angiography. Angiographic and MRA outcomes were determined by the treating physician and were classified according to the Raymond classification. An aneurysm was considered stable on follow-up if there was no increase in contrast filling on angiography or flow on MRA. Re-treatment was considered in persistent or evolving aneurysmal remnants.

\section{RESULTS}

\section{Patient Population and Aneurysm Characteristics}

Of the 295 patients, 196 (66.7\%) were women and 98 (33.3\%) were men. A total of 244 ruptured aneurysms in 242 patients and 56 unruptured aneurysms in 53 patients comprised the study cohort. The mean age of the patients in the ruptured cohort was 53.9 years; for the patients in the unruptured cohort, it was 52.7 years (Table 1). For the 242 patients with SAH, World Federation of Neurosurgical Societies (WFNS) and Fisher grading is shown in Table 1.

A total of 264 aneurysms ( $88 \%$ ) were located at the main MCA branching point; $23(7.7 \%)$ were positioned proximal to this location, and $13(4.3 \%)$ were positioned more distally. There were 232 aneurysms $(77 \%)$ that were small $(\leq 10 \mathrm{~mm})$ and $64(21 \%)$ that were large (11-24 mm). Giant aneurysms constituted $1.3 \%$ of the cohort (4 cases), and 93 aneurysms (31\%) were wide-neck ( $>4 \mathrm{~mm}$ ). Twenty patients $(8.3 \%)$ with SAH (other than those subsequently referred for clipping after a failed attempt at coiling) went on to have a craniotomy and hematoma evacuation or hemicraniectomy.

Surgical data were available from 2000-2012; 51 patients with 
Table 2: Initial coiling results

\begin{tabular}{lccc}
\hline \multicolumn{1}{c}{ Initial Angiographic Result } & $\begin{array}{c}\text { Unruptured } \\
\text { Aneurysms }(\boldsymbol{n}=\mathbf{5 6})\end{array}$ & $\begin{array}{c}\text { Ruptured } \\
\text { Aneurysms }(\boldsymbol{n}=\mathbf{2 4 4})\end{array}$ & \begin{tabular}{c} 
Total $(\boldsymbol{n}=\mathbf{3 0 0})$ \\
\hline Complete occlusion
\end{tabular} $2^{\text {Neck remnant }}$ \\
Aneurysm remnant & 17 & 186 & $215(71.7 \%)$ \\
Technical failure & 3 & 42 & $59(19.7 \%)$ \\
Complication precluding coiling & 5 & 6 & $9(3.0 \%)$ \\
Missing data & 1 & 8 & $13(4.3 \%)$ \\
\hline
\end{tabular}

Table 3: Complications and subsequent clinical outcomes

\begin{tabular}{lccccc}
\hline \multicolumn{1}{c}{ Complication } & Aneurysm Rupture & Thromboembolic & Early Rebleed & Other & Total \\
\hline Total number (\%) & $15(5.0)$ & $18(6)$ & $3(1.2)$ & $2(0.7)$ & $38(12.9)$ \\
Clinically silent (\%) & 6 & 6 & & 2 & $14(4.7)$ \\
GOS 5 & 7 & 10 & & 2 & 19 \\
GOS 4 & 5 & 2 & & & 7 \\
GOS 1 (\%) & 3 & 6 & 3 & & $12(4)$ \\
\hline
\end{tabular}

Table 4: Clinical outcomes for patients with ruptured MCA aneurysms

\begin{tabular}{lc}
\hline Clinical Outcome & Patients \\
\hline GOS 5 (\%) & $170(70.3)$ \\
GOS 4 (\%) & $23(9.5)$ \\
GOS 3 (\%) & $15(6.2)$ \\
GOS 2 & 0 \\
GOS 1 (\%) & $33(13.6)$ \\
Missing data (\%) & $1(0.4)$ \\
\hline
\end{tabular}

ruptured aneurysms underwent primary surgical clipping. A total of 36 patients were treated with primary clipping because of either lack of availability of an interventional neuroradiologist or if the patient was being treated by a vascular neurosurgeon (most aneurysms were clipped before 2003). Eight aneurysms were clipped because of anatomic considerations after angiography. In 13 cases, the patients were treated with clipping after attempted coiling. In the same period, 16 patients with unruptured MCA aneurysms were treated with elective primary clipping. The indications were patient choice or difficult aneurysmal morphologic features.

\section{Procedural Success}

Initial coiling results are summarized in Table 2. Technical failure was seen in 13 aneurysms ( 5 unruptured and 8 ruptured), equating to $4.3 \%$ of treated aneurysms. These patients went on to have microsurgical clipping.

A total of 215 aneurysms were completely occluded on initial conventional angiography (71.7\%), and neck remnant was seen in 59 patients $(19.7 \%)$, resulting in a rate of satisfactory occlusion of $91.4 \%$. An aneurysmal remnant was seen in 9 patients (3\%). In 2 patients, a complication precluded EVC.

\section{Complications}

Complications and clinical outcome are summarized in Table 3. The technical complication rate was $12.9 \%$, including aneurysmal perforations and thromboembolic events with either silent or transient symptoms. The overall permanent procedural-related morbidity rate was 3.8\% (11 patients) and mortality rate was $4 \%$ (12 patients), equating to a permanent morbidity and mortality rate of $7.8 \%$ (23 patients). Of those patients who experienced a technical complication, 26 (68.4\%) of 38 had a favorable outcome
(GOS, 4 or 5). When unruptured aneurysms were considered separately, 1 patient had transient arm weakness that fully resolved and 1 patient (1.8\%) died as a result of aneurysmal perforation, but no other permanent complications were encountered.

Aneurysmal Perforation. Fifteen patients ( $5 \%$ of procedures) had intraprocedural aneurysmal perforations. In 10 patients, the perforation occurred during coil insertion. In 1 patient, the perforation was secondary to remodeling balloon inflation; in another patient, perforation was secondary to contrast injection before intervention. When rupture occurred, heparin was reversed immediately with protamine; coiling continued to limit the extent of hemorrhage and occlude the aneurysm; and measures were used, if necessary, to reduce intracranial pressure via ventricular drainage of CSF. Six ruptures were clinically silent. Three patients died after rupture; 12 had an independent outcome (GOS, 4-5).

Thromboembolic Events. Eighteen patients (6\% of procedures) experienced thromboembolic complications. These were managed by intravenous aspirin and abciximab and induced hypertension. Of these thromboembolic complications, 6 were clinically silent and 3 were transient. Twelve patients were independent (GOS, $4-5)$, and 6 patients died.

Rebleeds. Three patients (1.2\%) experienced early rebleeds. All occurred within 24 hours of the procedure, and 3 patients died.

Other Complications. Coil protrusion was noted in 2 patients with no clinical sequelae.

\section{Clinical Outcome}

Of the patients with ruptured aneurysms, $79.8 \%$ had a favorable clinical outcome (GOS, 4-5). A total of 33 patients (13.6\%) died (Table 4). One of 53 patients with an unruptured aneurysm died as a result of procedural rupture and was the only patient who experienced a permanent change in neurologic status as a result of the procedure. Of the patients who underwent a craniotomy or craniectomy for management of hematoma or mass effect, 8 (40\%) of 20 achieved a clinical outcome of GOS 4 . The mortality rate was $45 \%$ in this subgroup.

\section{Anatomic Outcome}

Initial follow-up (mean, 7 months; range, 3-17 months) was available in 219 patients. Allowing for those patients who died, follow-up was available in $84 \%$. Reasons for no follow-up included a dead or severe outcome in 38 patients, advanced age in 12 patients, microsurgical clipping as a definitive treatment in 13 patients, patient choice in 7 patients, and unknown reasons in 6 patients.

Medium- to long-term follow-up (mean, 35 months; range, 18-108 months) was available in 158 patients. Twenty-two patients were ineligible because they were due this follow-up beyond the study period. Therefore, medium- to long-term follow-up was available in $80 \%$ of patients who had undergone initial follow-up 
Table 5: Angiographic outcomes at initial follow-up

\begin{tabular}{lcccc}
\hline \multicolumn{1}{c}{ Characteristic } & $\begin{array}{c}\text { Complete } \\
\text { Occlusion }\end{array}$ & $\begin{array}{c}\text { Neck } \\
\text { Remnant }\end{array}$ & $\begin{array}{c}\text { Aneurysm } \\
\text { Remnant }\end{array}$ & Re-treatment \\
\hline All aneurysms $(n=219)$ & $148(67.6 \%)$ & $53(23.3 \%)$ & $18(8.1 \%)$ & $13(5.9 \%)$ \\
Ruptured aneurysms $(n=175)$ & 117 & 42 & 16 & 13 \\
Unruptured aneurysms $(n=44)$ & 31 & 11 & 2 & 0 \\
Small $(\leq 10 \mathrm{~mm})$ & 137 & 26 & 11 & 6 \\
Large $(11-24 \mathrm{~mm})$ & 9 & 26 & 6 & 6 \\
Giant $(\geq 25 \mathrm{~mm})$ & 2 & 1 & 1 & 1 \\
Wide-neck $(>4 \mathrm{~mm})$ & 29 & 24 & 10 & 7 \\
\hline
\end{tabular}

surgery. Subsequent angiographic follow-up was available in these patients, and 5 achieved complete occlusion (including 1 patient who underwent microsurgery), 4 showed a neck remnant, and 4 showed a residual aneurysm. Stent or balloon-assisted coiling was used in 5 recurrent aneurysms. No morbidity or mortality was related to EVC.

\section{DISCUSSION}

and in $66 \%$ of the patients who were eligible for late follow-up and had survived the acute episode. Reasons for halting anatomic follow-up after initial follow-up were advanced age in 17 patients, out-of-region follow-up in 5 patients, patient choice in 12 patients, death from unrelated cause in 3 patients, and unknown reasons in 2 patients.

Initial angiographic follow-up is summarized in Table 5. Complete occlusion was seen in 148 aneurysms (67.6\%), a neck remnant was seen in $53(23.3 \%)$, and an aneurysmal remnant was seen in 18 aneurysms $(8.1 \%)$. Stable or improved appearances were seen in 178 $(81.3 \%)$ of 219 aneurysms. Twenty-three $(10.5 \%)$ showed minor anatomic deterioration to the neck remnant but remained satisfactorily occluded. Of those aneurysms with complete occlusion at postcoiling angiography undergoing initial follow-up $(n=164)$, the probability of complete occlusion was $84.1 \%$ (138 aneurysms), of a neck remnant was $12.2 \%$ (20 aneurysms), and of aneurysmal remnant was $3.6 \%$ ( 6 aneurysms). Of those aneurysms with a neck remnant at postcoiling angiography undergoing initial follow-up $(n=47)$, the probability of complete occlusion was 19.2\% (9 aneurysms), of a neck remnant was $70.2 \%$ (33 aneurysms), and of an aneurysmal remnant was $10.6 \%$ (5 patients).

A total of 18 aneurysms (8.1\%) showed an aneurysmal remnant at initial follow-up, 6 had shown a similar aneurysmal remnant on immediate postcoiling angiography, and 12 aneurysms demonstrated deterioration from complete occlusion or a neck remnant to an aneurysmal remnant. Aneurysmal remnants were more common in patients with large and giant aneurysms compared with small aneurysms at follow-up (15.6\% vs $6.3 \% ; P=$ $.04)$. Wide-neck aneurysms were also significantly more common in patients who showed an aneurysmal remnant at follow-up compared with those with complete occlusion (19.6\% vs $55.6 \%$; $P<.001)$. There were $13(4.3 \%)$ of these patients who were retreated (12 with further coiling and 1 with microsurgery). The remaining 5 patients showed a stable aneurysmal remnant and were treated conservatively.

A total of 158 patients underwent long-term follow-up: 110 patients (69.4\%) showed complete occlusion, 43 (27.4\%) showed a neck remnant, and $5(3.1 \%)$ showed an aneurysmal remnant. A total of 150 (95\%) patients, including the re-treated patients, showed stable appearances. A new neck remnant that did not warrant re-treatment was seen in 7 patients, and new aneurysmal remnant was seen in only 1 patient.

\section{Re-Treatment}

Twelve of 13 recurrent aneurysms were re-treated $(4.3 \%$ of all aneurysms) with coil embolization and 1 with microsurgical clipping. One of 12 endovascular patients required 4 additional treatments for a recurrent, large, wide-neck aneurysm; she refused
Controversy has existed as to the best mode of therapy for MCA aneurysms. The anatomy of MCA aneurysms is often considered more favorable for surgical treatment because of the frequency of a wide-neck configuration with incorporation of MCA branches that are technically more challenging to treat by EVC. ISAT demonstrated that $116(71.6 \%)$ of 162 endovascular patients and 100 (71.9\%) of 139 surgical patients attained independence (mRS, $0-2)^{8}$; however, MCA aneurysms were relatively underrepresented in ISAT, owing to the absence of clinical equipoise at the time of recruitment. This has led to criticism of the practice of applying ISAT to MCA aneurysms and the generalized adoption of EVC for aneurysms at this location. We therefore review the clinical and radiologic outcomes of this series in the context of the endovascular and surgical literature.

\section{Clinical Outcome in Patients with Ruptured Aneurysms}

Favorable clinical outcomes (mRS, 0-2) for ruptured aneurysms at all locations in ISAT ${ }^{1}$ and CLARITY ${ }^{9}$ (Clinical and Anatomical Results in the Treatment of Ruptured Intracranial Aneurysms, a multicenter prospective study of consecutively coiled patients) were $76.3 \%$ and $72.3 \%$, respectively, with the proportion of favorable presenting clinical grade patients (WFNS, 1-2) being $88 \%$ and $65.7 \%$, respectively. Favorable clinical outcomes (mRS, 0-2 and GOS, 5) in other large series of ruptured MCA aneurysms comprising at least 50 patients treated with EVC, are within the $67 \%-85 \%$ range. ${ }^{10-14}$

In the present study, the largest published single-center experience to date, patients with consecutive ruptured MCA aneurysms achieved good outcome (GOS, 5) in 70.3\% and favorable outcome (GOS, 4 and 5) in nearly $80 \%$, with the proportion of favorable presenting clinical grade patients (WFNS, 1-2) being $72 \%$. We were able to directly compare the results of our present study to a large audit of ruptured aneurysms at all locations treated through EVC at our institution with similar distribution of clinical grade. ${ }^{15}$ In this study, 711 patients with 717 ruptured aneurysms were reviewed. In the 605 patients with aneurysms at all locations other than the MCA, favorable outcome (GOS, 4 and 5) was seen in $490(80.9 \%)$. Mortality occurred in 89 patients (14.7\%). Statistical comparison of clinical outcomes for patients with ruptured MCA aneurysms in the present study showed no significant difference in the favorable outcome $(P=.58)$ or mortality $(P=.69)$.

Other than the ISAT ${ }^{8}$ results, prospective data on outcomes for clipping of ruptured MCA aneurysms are lacking. In 1990, The International Cooperative Study on the Timing of Aneurysm Surgery, ${ }^{16}$ a multicenter prospective observational study, included 786 patients with ruptured MCA aneurysms. A total of 480 pa- 
tients (61\%) achieved good outcome (GOS, 5) at 6 months. Following this, Rinne et $\mathrm{al}^{17}$ published one of the largest series of 561 patients with 690 MCA aneurysms, 91\% presenting with SAH and $80 \%$ with Hunt and Hess grades I-III. Overall favorable outcome (GOS, 5) was $60 \%$. Poor outcomes (GOS, 1-3) were seen in $32 \%$, and this rate was higher in large or giant aneurysms. It is surprising to note that there were significantly more poor outcomes among patients with ruptured MCAs than among those with any other anterior circulation aneurysms (32\% and 25\%, respectively).

After ISAT, several single-center studies have been published. Güresir et $\mathrm{al}^{18}$ treated 168 patients with ruptured MCA aneurysms. Favorable outcome (mRS, $0-2$ ) was $55 \%$ at 6 months. At the other end of the scale, among 80 patients treated by Van Dijk et $\mathrm{al}^{7}{ }^{7}$ including $67 \%$ with WFNS grades I-II, $80 \%$ achieved an mRS of $0-2$ at longer-term clinical follow-up (mean, 4.7 years). In one of the largest and most complete recent series, RodríguezHernández et $\mathrm{al}^{4}$ treated 282 ruptured MCA aneurysms with 78\% of patients presenting with Hunt and Hess grades I-III; favorable outcomes ( $\mathrm{mRS}, 0-2$ ) were achieved in $70.2 \%$.

These results are similar to those achieved in the present study by using EVC. Therefore, although the conservative view is that surgery should remain the treatment of choice of ruptured MCA aneurysms, except when there are extenuating comorbidities or overriding patient preferences, we believe that for the range of ruptured MCA aneurysms, at least equivalent clinical outcomes to the best surgical series can be obtained by use of conventional endovascular techniques.

\section{Coiling in the Presence of Intracerebral Hematoma}

One of the traditional advantages of a clipping strategy is that it allows hematoma evacuation. An alternative approach is to protect the aneurysm before evacuation through coiling. It is possible that this approach is more advantageous because hematoma evacuation in the presence of an unprotected aneurysm may initiate intraprocedural rupture. ${ }^{19}$ Furthermore, clipping may require a more extensive surgical exposure to access the aneurysm, perhaps involving retraction of contused parenchyma, which can result in edema or ischemia ${ }^{20}$; this would no longer be required. By use of this approach in the present series, of 20 patients with WFNS grades III or higher (14/20 were grades IV and V), $40 \%$ of patients achieved an outcome of GOS 4 . Other small series have also achieved more impressive outcomes in poor-grade patients by using this approach. ${ }^{21}$

\section{Technical Success}

The coiling procedure was successfully performed in $94.4 \%$ of aneurysms with posttreatment imaging, demonstrating that $71.7 \%$ were completely occluded and $19.7 \%$ exhibited a neck remnant, equating to a satisfactory occlusion rate of $91.4 \%$. The technical failure rate was $4.3 \%$. These results are very similar to the results of a systematic review of 12 series comprising a total of 1030 patients with $1076 \mathrm{MCA}$ aneurysms (500 patients had ruptured aneurysms, and 541 had unruptured aneurysms). ${ }^{22}$ In that study, the EVC failure rate was 4.8\% (95\% CI, 3.7\%-6.3\%). Overall, $82.4 \%$ (95\% CI, $80.0 \%-84.6 \%$ ) of MCA aneurysms were completely or nearly completely occluded at immediate postop- erative angiographic follow-up, and $12.7 \%$ (95\% CI, 10.9\%$14.9 \%$ ) were incompletely occluded. Prospective data specifically for MCA aneurysms are available from the results of the ATENA (Analysis of Treatment by Endovascular Approach of Nonruptured Aneurysms) study, which included 86 unruptured MCA aneurysms. ${ }^{23}$ Complete occlusion was achieved in $69.4 \%$, neck remnant in $19.4 \%$ (adequate occlusion in $88.8 \%$ ), and aneurysmal remnant in $11.3 \%$. In the CLARITY study, 105 MCA aneurysms were included. Complete occlusion was achieved in $45.7 \%$, neck remnant in 39\% (adequate occlusion in $84.7 \%$ ), and aneurysmal remnant in $15.2 \% .{ }^{24}$ It is important to note that though occlusion rates were lower in this study, the results did not differ significantly from other anterior circulation locations.

We hope that this case series dispels the contradictory conclusions of previous publications, ${ }^{2,3}$ suggesting that EVC is appropriate only in a minority of MCA aneurysms. Our experience, and the experience of others, concludes that EVC is feasible in most aneurysms.

\section{Short-Term Follow-Up}

Initial angiographic follow-up demonstrated satisfactory occlusion in $92 \%$ of aneurysms, with $8.1 \%$ showing residual aneurysm. A total of $81 \%$ of MCA aneurysms, most treated as part of a coilfirst policy, were stable or showed improved appearances at initial angiographic follow-up. A systematic review of 748 MCA aneurysms treated by endovascular means also showed angiographic stability or progression to better obliteration in $81 \%$ of patients undergoing follow-up angiography. ${ }^{22}$ In the CLARITY study, ${ }^{25}$ of 53 patients undergoing midterm follow-up, 57.4\% (95\% CI, $44.8-69.3)$ showed stability or improved appearances and $42.6 \%$ (95\% CI, 30.7-55.2) had shown some degree of anatomic worsening, but presumably, this was not significant in most because $77.9 \%$ (95\% CI, 66.2-87.1) were classified as having adequate occlusion. Although the rate of anatomic worsening was higher in other studies, the rate was very similar to that at other anatomic locations and was not specific for MCA aneurysms.

\section{Adjunctive Therapies}

In this series, bare platinum coils were the mainstay of treatment during a long enrollment period, with many aneurysms treated by use of old-generation technology. The use of adjunctive devices such as stent placement or balloon remodeling was very infrequent, and intra-aneurysmal flow diverters were not used. This trend may explain the relatively low thromboembolic complication rate, but also lower rates of complete occlusion compared with some recently published series on use of adjunctive devices. ${ }^{26,27}$ Adjunctive devices have been used in $20.4 \%$ of other published MCA series, ${ }^{22}$ with the aim of obtaining complete occlusion to minimize the risk for subsequent hemorrhage. ${ }^{28}$

A critical appraisal of the available literature has suggested that balloon assistance has a very similar safety profile to coiling without remodeling. ${ }^{29}$ In the CLARITY ${ }^{30}$ and ATENA ${ }^{31}$ studies, the use of a balloon was not associated with significantly increased rates of thromboembolic events or aneurysmal perforation but was associated with an increased rate of adequate postoperative occlusion. Vendrell et $\mathrm{al}^{32}$ treated $63 \mathrm{MCA}$ aneurysms with a balloon remodeling technique. It is interesting to note that they 
found that though this technique allowed treatment of aneurysms with more complex morphologic features, it was associated with more recurrences in the long term than were treatments without balloon remodeling.

Stent assistance may lower recurrence and allow more complete treatment of more complex lesions. However, there are reservations regarding procedural safety. Procedural morbidity and mortality risks have been shown to be significantly greater in those patients who have undergone stent-assisted coiling compared with those who have not undergone stent-assisted coiling. ${ }^{33}$ Procedural morbidity and mortality risks are significantly increased when treating ruptured aneurysms as opposed to unruptured aneurysms with a stent. ${ }^{34}$ Several series have recently been published that focus specifically on complex MCA aneurysms. ${ }^{26,27,35}$ In the largest series, Johnson et al $^{26}$ treated 100 MCA aneurysms with stent assistance. Follow-up imaging showed complete occlusion in $90.6 \%$ of aneurysms, residual neck in $3.5 \%$, and residual filling in 5.9\%. Four aneurysms (4.7\%) required re-treatment. Long-term MRA follow-up revealed stability or progressive thrombosis in $97.9 \%$. Permanent morbidity was seen in $1 \%$ and mortality in $1 \%$. These authors suggested that this treatment method represented a safe and acceptable alternative to craniotomy.

Intra-aneurysmal flow diverters now represent an additional treatment option for wide-neck bifurcation aneurysms. Pierot et $\mathrm{al}^{36}$ treated 34 ruptured and unruptured MCA aneurysms with the WEB device. Adequate occlusion (total occlusion or neck remnant) was observed in $83.3 \%$ of aneurysms with an acceptable safety profile; mortality rate of the treatment was $0.0 \%$ and morbidity rate was $3.1 \%$ (intraoperative rupture with an mRS of 3 at 1-month follow-up).

\section{Long-Term Follow-Up, Re-Treatment, and Surgical Occlusion Rates: Do They Confer a Long-Term Advantage?}

In the present series, $4.3 \%$ were re-treated. In other endovascular series of at least 50 patients, re-treatment rates varied from $2.4 \%-$ $13.9 \% .{ }^{10-14,32}$ It is well recognized that the decision to re-treat is highly variable. ${ }^{37}$ Our cohort had no additional morbidity or mortality relating to the additional procedures, and in line with previous findings, ${ }^{38,39}$ the risk for further coil embolization did not negate the advantage of the initial embolization. At late follow-up, including re-treated aneurysms, 157 of 158 aneurysms showed complete occlusion, neck remnant, or stable aneurysmal remnant. One case showed significant delayed anatomic deterioration.

Surgical series have shown high rates of complete occlusion. Each of the series published since ISAT have claimed excellent rates of initial complete aneurysm obliteration ranging from 89\%-98.3\%., ${ }^{4,78}$ Long-term angiographic follow-up was available in only $22 \%{ }^{4}$ and $29 \%{ }^{18}$ in 2 of these series but reported excellent rates of complete occlusion ranging from 96\%-98\%. This is perhaps one of the principal arguments for clipping aneurysms at any location; many of the reservations in the neurosurgical literature regarding the use of coiling stem from the lower rate of complete occlusion. A major limitation of this study was the lack of long-term morbidity data, and therefore, based on our data, long-term efficacy was unclear. However, the risk for rerupture occurs mostly within the first year. ${ }^{28,40}$ Beyond this, the risk lies between $0.11 \%{ }^{28}$ and $0.21 \%{ }^{40}$ per year. Both ISAT, ${ }^{40}$ CARAT (Cerebral Aneurysm Rerupture After Treatment), ${ }^{28}$ and BRAT (Barrow Ruptured Aneurysm Trial) ${ }^{41}$ studies have suggested that the benefits of coiling are unlikely to be superseded by the risk of delayed hemorrhage. The predicted risk has been calculated from the CARAT study, in which $57 \%$ showed a neck remnant, and ISAT, in which $27 \%$ showed a neck remnant. Prospectively acquired, independently assessed anatomic data have suggested that the neck remnant rate is not significantly different for MCA aneurysms vs other locations, ${ }^{25}$ and re-treatment rates, both in our own series and on systematic review of the literature, ${ }^{22}$ are not in excess of re-treatment rates at all anatomic locations. ${ }^{42}$ Therefore, the argument that endovascular MCA occlusion rates are low and result in a greater risk of rebleeding is unlikely to be true. The data from both CARAT and ISAT also raise the question of how aggressively to manage stable neck remnants. Most of these remnants are likely to be benign. We have noted a trend to manage neck remnants conservatively. This trend may be reflected in the proportion of re-treated patients in the more recent Cerecyte ${ }^{43}$ and HELPS (HydroCoil Endovascular Aneurysm Occlusion and Packing Study $)^{44}$ trials compared with ISAT (5.5\% and 3\%, respectively, vs $17 \%)$.

\section{Morbidity and Mortality Outcomes}

Aneurysmal perforation was seen in 5\% of patients, with permanent morbidity and mortality relating to this at $3 \%$. The perforation rate lies within the range of previously published studies that have demonstrated procedural perforation complicating $1 \%$ $8.5 \%$ of MCA aneurysm treatments. ${ }^{10-14,32}$ In 2 large prospective series of unruptured aneurysms (ATENA) ${ }^{45}$ and ruptured aneurysms (CLARITY) treated by endovascular means, the perforation rate for MCA aneurysms was $4.1 \%$ and $8.5 \%$, respectively. We have previously suggested that the rate of aneurysmal perforation may be higher at the MCA location ${ }^{15}$; we demonstrated that MCA aneurysms accounted for $13 \%$ of cases but $24 \%$ of all intraprocedural ruptures. In the CLARITY study, the frequency of procedural perforation was significantly higher in the MCA group compared with aneurysms at other locations, though the cumulative morbidity and mortality rates of procedural perforation were not significantly increased. ${ }^{46}$

The thromboembolic rate was $6 \%$, with permanent morbidity and mortality rate relating to this at $3 \%$. This rate is lower than in many large endovascular series ${ }^{10-14}$ and in prospective series ${ }^{45,46}$ that demonstrate thromboembolism complicating 7\%-19.6\%. We attributed this finding, at least in part, to the routine use of intravenous aspirin and low use of adjunctive devices, particularly stents. In other series, aspirin administration was not routine with ruptured aneurysms that comprised most aneurysms in this series. In the CLARITY study, ${ }^{46}$ although the rate of thromboembolic complications was not significantly higher in MCA aneurysms compared with those at other locations, the cumulative morbidity and mortality rate related to thromboembolic events was significantly higher in the MCA group than in the non-MCA group (7.5\% vs 3.3\%, respectively; $P=.038)$. Therefore, it was 
suggested that the clinical consequences of thromboembolism are important because of the size and function of the MCA territory.

In this study, 3 patients (1.2\%) experienced rebleeds and all died. All aneurysms appeared completely occluded on postprocedure angiography, and all occurred within the first 24 hours of the procedure. The CARAT study ${ }^{28}$ demonstrated a risk of rebleeding at all anatomic locations after complete occlusion by use of coiling to be $1.8 \%$ and clipping to be $0.9 \%$. It appears, therefore, that the results for MCA aneurysm coiling are not dissimilar to those for all locations.

\section{Surgical Morbidity and Mortality}

Published single-center surgical series specifically focusing on ruptured MCA aneurysms have variably reported procedural complication rates. Two recent series have described complication rates. Güresir et $\mathrm{al}^{18}$ described infarction complicating 5.5\% of cases and periprocedural hemorrhage complicating 5.5\% of cases in their series of 168 cases. Rodríguez-Hernández et $\mathrm{al}^{4}$ reported the procedural-related combined morbidity and mortality to be $1.1 \%$ in a series of 282 ruptured MCA aneurysms. Intraprocedural rupture occurred in $7.5 \%$, but there was no permanent morbidity or mortality relating to this. These results are very impressive and reflect a highly specialized service, but we do question whether they can be generalized to the neurosurgical community as a whole, particularly to centers with modest volume. Indeed, data base analysis of a large US population (2454 patients) with ruptured aneurysms from 2006-2011 at multiple centers demonstrated that patients treated with clipping demonstrated an increased likelihood of morbidity, as defined by hospital discharge to long-term care facilities, ischemic complications, and other postoperative complications, compared with patients treated with coiling. ${ }^{47}$ Prospective data on procedural morbidity and mortality relating to ruptured MCA aneurysm clipping are lacking, but data from the PRESAT (Prospective Registry of Subarachnoid Aneurysms Treatment) trial $^{48}$ (40.5\% of surgical cases were MCA aneurysms) show an overall clipping-related complication rate of $17.2 \%$. This rate included intraoperative rupture in $6.7 \%$, ischemic complications in $6 \%$, and hemorrhagic complications in $5.4 \%$ (the latter included parenchymal contusions, extradural and subdural hematomas, and primary hematoma extension).

An additional potential drawback of the use of open neurosurgery is the risk for epilepsy. This finding was not assessed in the present series, but in late follow-up of ISAT, ${ }^{49}$ it has been demonstrated that MCA location is associated with an increased epilepsy risk for both coiling and clipping but that this risk is significantly greater in patients who had undergone clipping. In the coiling group, the risk for epilepsy at 1 year was $2.6 \%$ for non-MCA locations compared with $6.5 \%$ for MCA aneurysms. At 5 years, the cumulative risk was $10.3 \%$ for the MCA location. For clipping, the risk at 1 year for nonMCA locations was $4.3 \%$, but for MCA aneurysms, this risk was $11.5 \%$ and at 5 years, the cumulative risk was $21.7 \%$.

\section{Surgical and Endovascular Treatment of Unruptured MCA Aneurysms}

A safety profile is key to an effective treatment in the elective setting. In the endovascular cohort of ISUIA (International Study of Unruptured Intracranial Aneurysms), ${ }^{50}$ mortality rate was $1.7 \%$ and morbidity rate (mRS, $3-5$ ) was $2.2 \%$ in 451 patients. In our cohort of patients with unruptured aneurysms, the mortality rate was $1.8 \%$. There was no permanent morbidity. The prospective ATENA ${ }^{45}$ study was not powered to compare outcomes by anatomic location, but the rate of thromboembolism and aneurysm perforation was $9.6 \%$ and $4.1 \%$, respectively, for the MCA location and overall morbidity and mortality rate was $1.7 \%$ and $1.4 \%$, respectively. A systematic review ${ }^{22}$ of 500 patients with 541 unruptured MCA aneurysms treated at 12 centers by EVC demonstrated a permanent procedural morbidity rate of $5.1 \%$ and a mortality rate of $0.3 \%$. ATENA also demonstrated no difference in anatomic occlusion between the MCA and other anterior circulation aneurysms.

For unruptured aneurysms, several large surgical series from high-volume centers have demonstrated an excellent procedural safety profile, with morbidity rates ranging from $2 \%-6 \%$ and mortality rates from $0 \%-2 \% .{ }^{4-6,51}$ In 2 studies, ${ }^{5,51}$ approximately half of all aneurysms treated were $<5 \mathrm{~mm}$ and most were $<10 \mathrm{~mm}$ in size. This characteristic may well have contributed to the good outcomes, as it is evident that increasing age and aneurysm size are associated with increasing surgical morbidity rates. In the largest series of 263 patients with 339 aneurysms who underwent surgical clipping in 280 operations, Morgan et al ${ }^{6}$ assessed risk based on age and aneurysm size. Patients $<60$ years old with an aneurysm $\leq 12 \mathrm{~mm}$ constituted a low-risk group with a procedural-related combined mortality and morbidity rate of $0.6 \%$ (95\% CI, $0-3.8$ ). Patients $<60$ years old with an aneurysm $>12 \mathrm{~mm}$ had a procedural-related combined mortality and morbidity rate of $7.4 \%$ ( $95 \%$ CI, 1-24.5). Patients $\geq 60$ years old with an aneurysm size of $\leq 12 \mathrm{~mm}$ had a procedural-related combined mortality and morbidity rate of $9.3 \%$ (95\% CI, 4.3-18.3). Patients $\geq 60$ years old with an aneurysm size of $>12 \mathrm{~mm}$ had a procedural-related combined mortality and morbidity rate of $22.2 \%$ (95\% CI, 8.5-45.8).

These data suggest a good safety profile for small aneurysms but do raise the specific question of whether EVC would be more appropriate for older patients with larger aneurysms. Furthermore, whether the results of these surgical series can be extrapolated to general neurosurgical practice is questionable. Multicenter data are limited, but one source is the ISUIA study. MCA aneurysms comprised $29 \%$ of the prospective ISUIA cohort, and surgical-related morbidity and mortality was seen in $13.7 \%$ of patients. ${ }^{50}$ International Classification of Diseases code data base analysis of 2535 patients with unruptured aneurysms treated between 1998 and 2000 demonstrated that EVC was associated with fewer adverse outcomes (6.6\% vs $13.2 \%)$, decreased mortality rates $(0.9 \%$ vs $2.5 \%)$, and shorter lengths of hospital stay ( 4.5 vs 7.4 days).$^{52}$ Using a similar, but larger data base analysis of patients treated between 2001 and 2008, Brinjikji et $\mathrm{al}^{53}$ showed that the percentage of patients discharged from the hospital to longterm facilities was $14.0 \%(4184 / 29,918)$ for patients who underwent clipping compared with $4.9 \%(1655 / 34,125)$ of patients who were treated with coiling $(P<.0001)$. Patients who received clipping also had a higher mortality rate because 344 (1.2\%) of these patients died compared with $215(0.6 \%)$ of patients who received coiling $(P<.0001)$. 


\section{CONCLUSIONS}

Most MCA aneurysms can be effectively treated with EVC, achieving satisfactory rates of occlusion with acceptable safety profiles and rates of favorable outcome. For ruptured aneurysms, clinical results are similar to those for aneurysms at other locations and also to those achieved in many surgical series. The clinical and anatomic results of this series are also similar to those of a recently published systematic review, suggesting that they are repeatable. Recurrence is, not unexpectedly, more common in giant, large, and wide-neck aneurysms, but results of prospective trials suggest that anatomic results are not dissimilar to other anatomic locations. Therefore, the endovascular approach to MCA aneurysms is justifiable.

Disclosures: Marcus Bradley—UNRELATED: Grants/Grants Pending: Covidien,* Comments: Funding for nurses and trainees in the form of an educational grant; Travel/Accommodations/Meeting Expenses Unrelated to Activities Listed: Travel and accommodation expenses from ev3 for attendance at a meeting regarding the Pipeline device in 2012 (expenses paid directly) Travel and accommodation expenses for attendance at the American Society of Neuroradiology meeting in 2011 covered by ev3 (expenses paid directly); Other: Meals provided by Stryker during attendance at biannual morbidity and mortality meetings. Andrew Molyneux-UNRELATED: Consultancy: Sequent Medical, Comments: Current agreement, but postdated the case series. Shelley Renowden-UNRELATED: Travel/Accommodations/Meeting Expenses Unrelated to Activities Listed: Travel expenses/accommodation paid by Stryker and Covidien to overseas meetings. ${ }^{*}$ Money paid to institution.

\section{REFERENCES}

1. Molyneux A, Kerr R, Stratton I, et al. International Subarachnoid Aneurysm Trial (ISAT) of neurosurgical clipping versus endovascular coiling in 2143 patients with ruptured intracranial aneurysms: a randomised trial. Lancet 2002;360:1267-74

2. Ausman JI. The future of neurovascular surgery. Part I: Intracranial aneurysms. Surg Neurol 1997;48:98-100

3. Regli L Uske A, de Tribolet N. Endovascular coil placement compared with surgical clipping for the treatment of unruptured middle cerebral artery aneurysms: a consecutive series. J Neurosurg 1999;90:1025-30

4. Rodríguez-Hernández A, Sughrue ME, Akhavan S, et al. Current management of middle cerebral artery aneurysms: surgical results with a "clip first" policy. Neurosurgery 2013;72:415-27

5. Choi SW, Ahn JS, Park JC, et al. Surgical treatment of unruptured intracranial middle cerebral artery aneurysms: angiographic and clinical outcomes in 143 aneurysms. J Cerebrovasc Endovasc Neurosurg 2012;14:289-94

6. Morgan MK, Mahattanakul W, Davidson A, et al. Outcome for middle cerebral artery aneurysm surgery. Neurosurgery 2010;67:755-61

7. van Dijk JM, Groen RJ, Ter Laan M, et al. Surgical clipping as the preferred treatment for aneurysms of the middle cerebral artery. Acta Neurochir (Wien) 2011;153:2111-17

8. Molyneux AJ, Kerr RS, Yu LM, et al. International Subarachnoid Aneurysm Trial (ISAT) of neurosurgical clipping versus endovascular coiling in 2143 patients with ruptured intracranial aneurysms: a randomised comparison of effects on survival, dependency, seizures, rebleeding, subgroups, and aneurysm occlusion. Lancet 2005;366:809-17

9. Cognard C, Pierot L, Anxionnat R, et al. Results of embolization used as the first treatment choice in a consecutive nonselected population of ruptured aneurysms: clinical results of the Clarity GDC Study. Neurosurgery 2011;69:837-41

10. Iijima A, Piotin M, Mounayer C, et al. Endovascular treatment with coils of 149 middle cerebral artery berry aneurysms. Radiology 2005;237:611-19

11. Quadros RS, Gallas S, Noudel R, et al. Endovascular treatment of middle cerebral artery aneurysms as first option: a single center experience of 92 aneurysms. AJNR Am J Neuroradiol 2007;28: $1567-72$

12. Suzuki S, Tateshima S, Jahan R, et al. Endovascular treatment of middle cerebral artery aneurysms with detachable coils: angiographic and clinical outcomes in 115 consecutive patients. Neurosurgery 2009;64:876-88; discussion 888-89

13. Bracard S, Abdel-Kerim A, Thuillier L, et al. Endovascular coil occlusion of 152 middle cerebral artery aneurysms: initial and midterm angiographic and clinical results. J Neurosurg 2010;112:703-08

14. Oishi H, Yoshida K, Shimizu T, et al. Endovascular treatment with bare platinum coils for middle cerebral artery aneurysms. Neurol Med Chir (Tokyo) 2009;49:287-93

15. Renowden SA, Benes V, Bradley M, et al. Detachable coil embolisation of ruptured intracranial aneurysms: a single center study, a decade experience. Clin Neurol Neurosurg 2009;111:179-88

16. Kassell NF, Torner JC, Haley EC, et al. The International Cooperative Study on the Timing of Aneurysm Surgery. Part 1: Overall management results. J Neurosurg 1990;73:18-36

17. Rinne J, Hernesniemi J, Niskanen M, et al. Analysis of $\mathbf{5 6 1}$ patients with 690 middle cerebral artery aneurysms: anatomic and clinical features as correlated to management outcome. Neurosurgery 1996;38:2-11

18. Güresir E, Schuss P, Berkefeld J, et al. Treatment results for complex middle cerebral artery aneurysms. A prospective single-center series. Acta Neurochir (Wien) 2011;153:1247-52

19. Houkin K, Kuroda S, Takahashi A, et al. Intra-operative premature rupture of the cerebral aneurysms. Analysis of the causes and management. Acta Neurochir (Wien) 1999;141:1255-63

20. Yundt KD, Grubb RL Jr, Diringer MN, et al. Cerebral hemodynamic and metabolic changes caused by brain retraction after aneurysmal subarachnoid hemorrhage. Neurosurgery 1997;40:442-50

21. Tawk RG, Pandey A, Levy E, et al. Coiling of ruptured aneurysms followed by evacuation of hematoma. World Neurosurg 2010;74:626-31

22. Brinjikji W, Lanzino G, Cloft HJ, et al. Endovascular treatment of middle cerebral artery aneurysms: a systematic review and singlecenter series. Neurosurgery 2011;68:397-402; discussion 402

23. Pierot L, Spelle L, Vitry F, et al. Immediate anatomic results after the endovascular treatment of unruptured intracranial aneurysms: analysis of the ATENA series. AJNR Am J Neuroradiol 2010;31:140-44

24. Pierot L, Cognard C, Ricolfi F, et al. Immediate anatomic results after the endovascular treatment of ruptured intracranial aneurysms: analysis in the CLARITY series. AJNR Am J Neuroradiol 2010;31:907-11

25. Pierot L, Cognard C, Anxionnat R, et al. Endovascular treatment of ruptured intracranial aneurysms: factors affecting midterm quality anatomic results: analysis in a prospective, multicenter series of patients (CLARITY). AJNR Am J Neuroradiol 2012;33:1475-80

26. Johnson AK, Heiferman DM, Lopes DK. Stent-assisted embolization of 100 middle cerebral artery aneurysms. J Neurosurg 2013;118:950-55

27. Vendrell JF, Costalat V, Brunel H, et al. Stent-assisted coiling of complex middle cerebral artery aneurysms: initial and midterm results. AJNR Am J Neuroradiol 2011;32:259-63

28. Johnston SC, Dowd CF, Higashida RT, et al. Predictors of rehemorrhage after treatment of ruptured intracranial aneurysms: the Cerebral Aneurysm Rerupture After Treatment (CARAT) study. Stroke 2008;39:120-25

29. Pierot L, Cognard C, Spelle L, et al. Safety and efficacy of balloon remodeling technique during endovascular treatment of intracranial aneurysms: critical review of the literature. AJNR Am J Neuroradiol 2012;33:12-15

30. Pierot L, Cognard C, Anxionnat R, et al. Remodelling technique for endovascular treatment of ruptured intracranial aneurysms had a higher rate of adequate postoperative occlusion than did conventional coil embolization with comparable safety. Radiology 2011;258:546-53 
31. Pierot L, Spelle L, Leclerc X, et al. Endovascular treatment of unruptured intracranial aneurysms: comparison of safety of remodeling technique and standard treatment with coils. Radiology 2009;251: 846-55

32. Vendrell JF, Menjot N, Costalat V, et al. Endovascular treatment of 174 middle cerebral artery aneurysms: clinical outcome and radiologic results at long-term follow-up. Radiology 2009;253:191-98

33. Piotin M, Blanc R, Spelle L, et al. Stent-assisted coiling of intracranial aneurysms: clinical and angiographic results in 216 consecutive aneurysms. Stroke 2010;41:110-15

34. Chalouhi N, Jabbour P, Singhal S, et al. Stent-assisted coiling of intracranial aneurysms: predictors of complications, recanalization, and outcome in 508 cases. Stroke 2013;44:1348-53

35. Fields JD, Brambrink L, Dogan A, et al. Stent assisted coil embolization of unruptured middle cerebral artery aneurysms. J Neurointerv Surg 2013;5:15-19

36. Pierot L, Klisch J, Cognard C, et al. Endovascular WEB flow disruption in middle cerebral artery aneurysms: preliminary feasibility, clinical, and anatomical results in a multicenter study. Neurosurgery 2013;73:27-34; discussion 34-35

37. McDonald JS, Carter RE, Layton KF, et al. Interobserver variability in retreatment decisions of recurrent and residual aneurysms. AJNR Am J Neuroradiol 2013;34:1035-39

38. Renowden SA, Koumellis P, Benes V, et al. Retreatment of previously embolized cerebral aneurysms: the risk of further coil embolization does not negate the advantage of the initial embolization. AJNR Am J Neuroradiol 2008;29:1401-04

39. Campi A, Ramzi N, Molyneux AJ, et al. Retreatment of ruptured cerebral aneurysms in patients randomized by coiling or clipping in the International Subarachnoid Aneurysm Trial (ISAT). Stroke 2007;38:1538-44

40. Molyneux AJ, Kerr RS, Birks J, et al. Risk of recurrent subarachnoid haemorrhage, death, or dependence and standardised mortality ratios after clipping or coiling of an intracranial aneurysm in the International Subarachnoid Aneurysm Trial (ISAT): long-term follow-up. Lancet Neurol 2009;8:427-33

41. McDougall CG, Spetzler RF, Zabramski JM, et al. The Barrow Ruptured Aneurysm Trial. J Neurosurg 2012;116:135-44

42. Ferns SP, Sprengers ME, van Rooij WJ, et al. Coiling of intracranial aneurysms: a systematic review on initial occlusion and reopening and retreatment rates. Stroke 2009;40:e523-29

43. Molyneux AJ, Clarke A, Sneade M, et al. Cerecyte Coil Trial: angiographic outcomes of a prospective randomized trial comparing en- dovascular coiling of cerebral aneurysms with either Cerecyte or bare platinum coils. Stroke 2012;43:2544-50

44. White PM, Lewis SC, Gholkar A, et al. Hydrogel-coated coils versus bare platinum coils for the endovascular treatment of intracranial aneurysms (HELPS): a randomised controlled trial. Lancet 2011; 14:377:1655-62

45. Pierot L, Spelle L, Vitry F, et al. Immediate clinical outcome of patients harboring unruptured intracranial aneurysms treated by endovascular approach: results of the ATENA study. Stroke 2008;39:2497-504

46. Pierot L, Cognard C, Anxionnat R, et al. Ruptured intracranial aneurysms: factors affecting the rate and outcome of endovascular treatment complications in a series of $\mathbf{7 8 2}$ patients (CLARITY study). Radiology 2010;256:916-23

47. McDonald JS, McDonald RJ, Fan J, et al. Comparative effectiveness of ruptured cerebral aneurysm therapies: propensity score analysis of clipping versus coiling. AJNR Am J Neuroradiol 2013 Jul 18 [Epub ahead of print]

48. Taki W, Sakai N, Suzuki H, et al. Determinants of poor outcome after aneurysmal subarachnoid hemorrhage when both clipping and coiling are available: Prospective Registry of Subarachnoid Aneurysms Treatment (PRESAT) in Japan. World Neurosurg 2011; 76:437-45

49. Hart Y, Sneade M, Birks J, et al. Epilepsy after subarachnoid hemorrhage: the frequency of seizures after clip occlusion or coil embolization of a ruptured cerebral aneurysm: results from the International Subarachnoid Aneurysm Trial. Neurosurg 2011; 115:1159-68

50. Wiebers DO, Whisnant, JP, Huston J 3rd, et al. Unruptured intracranial aneurysms: natural history, clinical outcome, and risks of surgical and endovascular treatment. Lancet 2003;362:103-10

51. Moroi J, Hadeishi H, Suzuki A, et al. Morbidity and mortality from surgical treatment of unruptured cerebral aneurysms at Research Institute for Brain and Blood Vessels-Akita. Neurosurgery 2005; 56:224-31

52. Higashida RT, Lahue BJ, Torbey MT, et al. Treatment of unruptured intracranial aneurysms: a nationwide assessment of effectiveness. AJNR Am J Neuroradiol 2007;28:146-51

53. Brinjikji W, Rabinstein AA, Lanzino G, et al. Effect of age on outcomes of treatment of unruptured cerebral aneurysms: a study of the National Inpatient Sample 2001-2008. Stroke 2011; 42:1320-24 